\title{
Rethinking PowerPoint Slide Design for Multimedia Learning
}

Luke LeFebvre, Megan M. Parsons, Charlotte Entwistle, Ryan L. Boyd, and Mike Allen 


\begin{abstract}
This analysis investigates two differential PowerPoint slide designs_-presentation and teleprompter-for multimedia learning. Eye tracking measures assessed differences in fixations. Participants demonstrated greater fixation counts for teleprompter slides, measures of aesthetic liking evidenced that slides incorporating imagery resulted in more pleasurable learning experiences, and visually-based slides influenced more reflective learning and greater activation of information processing. The results offer practical advice for instructors wishing to increase the slide design effectiveness for improved multimedia learning.
\end{abstract}

Keywords: multimedia learning, slideware technology, presentations, PowerPoint 


\section{Rethinking PowerPoint Slide Design for Multimedia Learning}

In the early 19th century, classroom pedagogical practices pivoted from a heavily didactic emphasis—relying almost exclusively on textual representations using printed books and lectures — towards the visual (drawings, pictures, etc.) (Depaepe, 2000). This shift in educational practice encouraged teachers to adopt the use of visual images in classroom spaces (Nelson, 2000). From the turn of the 20th century to the present, teachers were pressured to incorporate media technologies into teaching (Herting et al., 2020). This multimedia learning occurs when learners receive information presented in more than one mode, such as visual representations and verbal discourse (Mayer, 1997). The advancement of multimedia education technology has developed at such an exponential rate that a corresponding understanding of how learners select, organize, and integrate information in multimedia environments is unclear (Reiber, 1990). College classrooms in particular have been customarily retrofitted with presentational multimedia technology for teaching and learning (Motamedi, 2019).

The most predominant delivery media used in college classrooms is slideware technology (Inoue-Smith \& Wang, 2016). A slideware technology infuses visual communication components to enhance student learning, interest, and engagement (Mann \& Robinson, 2013) by blending visual images, text, sound, color, and animation (Penciner, 2013). The most omnipresent form of slideware technology in college classrooms is Microsoft PowerPoint (Axtell et al., 2008).

The pervasiveness of PowerPoint use in the classroom is not disputed, and its technological purpose is clear-to improve the sharing of ideas or information. A meta-analysis of the effectiveness of PowerPoint demonstrates improved effectiveness in cognitive learning but only compared the impact to lecture without multimedia learning (Shapiro et al., 2006). The 
question of how best to use the multimedia tool remains more open for exploration. Particularly, how slides within the slide deck are visually designed to influence what an audience sees, interprets, and recalls (Bucher \& Niemann, 2012). As a software, PowerPoint is compatible and transferable between electronic devices, but not all PowerPoint slide designs are created equal. PowerPoint's slide templates and themes allow the user to adlib, invent, and create unique visual narratives, which should be investigated to explore what slide design strategies are superior for learners.

This study contributes to the current body of literature surrounding multimedia learning via slideware technology. The goals of this research effort are threefold: (1) identify differences in eye fixation, (2) examine the extent to which viewers report responses of aesthetic pleasure resulting from engagement, and (3) explore how learners actively engage with and process the information shared through differential slide design layouts. The results intend to provide practical advice to optimize and advise the development and execution multimedia learning.

\section{Multimedia Learning}

Multimedia learning maintains that effective learning is most optimal when learners are able to construct and coordinate visual and verbal representations of the same material (Wang et al., 2019). Learners are knowledge curators who actively select, organize, and integrate verbal and visual information (Mayer, 1997). The design of multimedia instruction impacts the degree learners are able to engage and cognitively process course content (verbal and visual) for meaningful learning (Mayer \& Sims, 1994). Therefore, the learner must choose what verbal and visual information will be coherently organized for memory integration and recall. Slideware technology has the potential to display both visual representations and text to accompany the 
verbal discourse of an instructor's lecture. What is unclear is how slide design influences learners referential processing (Paivio, 1986).

\section{Slideware Technology and Slide Design}

In the 1990s and 2000s, limited guidance existed for PowerPoint users (Endicott, 2000). Microsoft offered few formatting suggestions for authoring slide decks, otherwise known as template layouts. These traditional layouts remained virtually unchanged in appearance since the feature was introduced (Cooper, 2009). The default layouts became the traditional style of PowerPoint offered to the user when launching the program. The style became embedded as the standardized design for experienced professionals, instructors, and students such that strong resistance exists to the consideration of design alternatives (Alley \& Neeley, 2005).

Visual communication research (e.g., visual processing fluency, aesthetic liking) for instructional environments provide evidence to support integrating intelligent use of slideware technologies (Savoy et al., 2008). Intelligent use of slideware technology best utilizes the abilities of slideware technology to control presentation variables so that the user will have a greater chance of relaying powerful messages in tandem to their oral presentation (Alley \& Neeley, 2005). Intelligent use of slideware technology directly relates to the slide design assembled across slides and slide decks.

Slide designs can be sorted into two predominate slide categories: teleprompter and presentation. Teleprompter slides (another version of text-only slides) use bullet points with limited text, and a word count of approximately 50 words (Garrett, 2015; Reynolds, 2012). Presentation slides (mixed slides) focus on displaying visuals rather than text alone and establish a visual narrative to punctuate and accompany the speaker’s spoken narrative (Duarte, 2008; Vazquez \& Chiang, 2014) with extremely limited text (see Figure 1). 
Slideware technology (Reynolds, 2012), enhances shared information via visual resources (Bucher \& Niemann, 2012). Visual attention can be measured by means of eye tracking, determined by fixations (Zagermann et al., 2016). Eye tracking research (Rello et al., 2013) uses fixation count and fixation duration to measure visual attention and processing. This study examines different PowerPoint slide designs and how learners view these visuals. The following research questions are posited:

$R_{\mathbf{1 A}_{1 A}}$ : Does fixation duration differ for participants processing different visual slide design representations displayed on slideware technology?

$\boldsymbol{R Q}_{1 B:}$ Does fixation count differ for participants processing different visual slide design representations displayed on slideware technology?

\section{Processing Fluency and Aesthetics}

The degree of viewer ease experienced when processing a visual denotes processing fluency (Reber et al., 2004). Aesthetics describe an ease of viewing offering a sense of pleasure experienced by the perceiver (Davies et al., 2009). A proposed theoretical framework (see Reber et al., 2004) assumes processing fluency and aesthetics are inherently linked. This proposal suggests that when viewers can easily process an object, they will experience a proportionately positive aesthetic response. Beauty, then, becomes grounded in the viewer's processing experiences, characterized by a pleasurable subjective experience. The process of visual aesthetic thought, as it pertains to visual communication, is illustrated with the inclusion of three primary actors: maker, viewer, and object (Dake, 2005).

The maker is the individual responsible for the visual message conveyance, while the viewer is the individual processing said message. This process considers the object to be the visual message's matter, which is delivered to incite an aesthetically pleasing experience. In a 
classroom environment, the PowerPoint slide deck provides the visual object interacted with by both student and instructor. The instructor acts as both the designer of the slides as well as the lecturer delivering the content. The viewer (student) processes the messages from both the slide deck and the instructor simultaneously. Exploring how learners respond to differences in slide design improves decision making for creating and using PowerPoint or similar slideware technology. The following research question is proposed:

$\boldsymbol{R} \boldsymbol{Q}_{2}$ : What type of slide designs — teleprompter or presentation-will participants report as most aesthetically pleasurable?

\section{Reflective Learning, Active Information Processing and Verbal Behavior}

To gain insight into how individuals process and learn information, it is important to explore the underlying psychological processes. In the current study, it is assumed that both reflective learning and active information processing will play a major role in differential processing of PowerPoint presentations. Specifically, reflective learning involves the internalization of information and processing of information in the context of one's self and one’s own experiences (Coulson \& Harvey, 2013), and has been evidenced to strongly influence the learning process and learning outcomes (e.g., Perusso et al., 2020). Active information processing consists of conscious activity from the learner, such as mental organization and attentional focus, accompanied by major cognitive investment (Mayer, 2001). Such active processing has been associated with increased engagement with learning materials, and thus, better learning outcomes (e.g., Chi \& Wylie, 2014). Exploration of reflective learning and active information processing should provide insight into how different PowerPoint designs may influence such low-level learning processes. 
The ways in which people use language - that is, their verbal behavior - has been shown to reflect the psychological state, including thinking styles, attentional patterns, and emotional states (Boyd \& Schwartz, 2021). Specifically regarding active information processing, use of “cognitive processing” language, such as insight words (e.g., think, know), reflects one's current cognitive state and one’s thought processes about specific events (Tausczik \& Pennebaker, 2010). Looking at people’s cognitive processing and analytic language allows an implicit measure of active information processing. Language can also provide insight into this process given that use of self-referential language, or $I$-words, in the context of learning reflects selfdirected attentional focus and internalization of learning. If an individual uses a considerable amount of self-referential language when discussing the PowerPoint material, this implies that they are actively involving "the self” in how they understand the learning process.

Accordingly, the exploration and analysis of people's language patterns makes it possible to infer and understand current psychological, reflective, and cognitive processes in respect to the experience and processing different designs. The final posited research question:

$\boldsymbol{R Q}_{3}$ : How does participants' verbal behavior in discussions of the visual slides differ based on the slide design representation being processed?

\section{Methods}

\section{Participants}

This study received approval from the university’s Institutional Review Board (IRB) for online recruitment of undergraduate students $(N=147)$ participating at a large southern university receiving extra credit for participation. Participants reported demographics: 70.1\% female, 98\% US citizens (61.9\% Caucasian, 19\% Hispanic, 4.8\% African American, 5.4\% Asian, 0.7\% Native Americans, 1.4\% Middle Eastern, 6.8\% two or more races). Participants' 
ages ranged from 18 to $50(M=20.9, S D=4.44)$. Participants were $27.9 \%$ freshmen, $16.3 \%$ sophomores, 32\% juniors, $23.1 \%$ seniors, and $0.7 \%$ unidentified.

\section{Procedures}

Participants viewed a PowerPoint (a) teleprompter $(n=75)$ or $(b)$ presentation slide $(n=$ 72) deck design displayed in a 16:10 aspect ratio. Two slide decks were produced, each exhibiting characteristics from either teleprompter or presentation slide design covering the identical lecture content. Both teleprompter and presentation slide decks contained 11 total slides and were four minutes and 29 seconds in length. The teleprompter slide deck used one of PowerPoint's automated layout design suggestions that best fit the criteria of a teleprompter style slide. Refer to Table 1 for a slide deck characteristics.

Table 1.

Slide Deck Characteristics.

\begin{tabular}{lcc} 
& Presentation & Teleprompter \\
\hline Typeface & Sans Serif & Serif \\
Font Size & $48-250$ & $48-80$ \\
Slide Transitions & Push & -- \\
Animations & -- & -- \\
Color Template & -- & -- \\
Slide Template & -- & Title and Content \\
Images & 10 & -- \\
Number of Slides & 11 & 11 \\
\hline
\end{tabular}

Two videos were prepared by screen recording a slide deck synced to congruent audio. The verbal narrative ensured both slide decks were advanced simultaneously and had the same duration of participant optical viewing. Participants were not able to advance the slides on their own and consistently experienced similar exposure time to lecture content both visually and auditorily. 
Upon entering the lab, participants sat at a desk fitted with an eye tracking monitor. They were seated in a fixed chair, to minimize movement for accurate measurement. Participants were briefed on the activities pertaining to the data collection process. The session lasted approximately 15-minutes_-including a calibration test, viewing the PowerPoint presentation video depicting a slide deck with voiceover narration, and survey. The researcher remained present during data collection to manage media and equipment.

After calibration achieved, the participant affixed headphones to hear the audio narration as a crosshair appeared at the exact center of the screen. The crosshair centers the participants' optical fixations at a consistent point before recording. Participants then pressed the spacebar on the keyboard to start the video. After the presentation, participants completed a survey related to aesthetic pleasure.

\section{Assessment and Measures}

\section{Eye Tracking: Fixation Duration and Fixation Count}

Answering the first research questions involved eye tracking measured by a remote optics eye tracking system mounted to the computer screen bottom. The Tobii X2-60 eye tracker model captures gaze data for fixation-based research through infrared light for unobtrusive viewing.

The eye tracker device, which captures gaze data at $60 \mathrm{~Hz}$, allows for freedom of head movement and reports gaze accuracy within $0.4^{\circ}$ visual angle. The coordinate measures recorded directional paths of movement, stationary points, and duration of eye fixations in real-time to determine interest in a particular screen area.

For this study, a fixation measurement is classified as a point of optical focus within 35 pixels lasting at least 100 ms. Unlike saccades, the quick continuous movements between fixations, fixations represent the voluntary stabilizations interpreted as evidence of the visual 
information processing (Zagermann et al., 2016). Total fixation duration (TFD) and fixation count (FC) were chosen as measures to better understand how participants engaged with different slide designs. TFD measures the total amount of time, on average, that participants spent fixating on the slide as opposed to searching or surveying. FC measures how many instances of fixation occur on average during the video. Higher levels of fixation duration are related to a higher level of cognitive processing with an increased strain on the viewer's working memory. The more complex the visual, the more complex the task for the viewer to make sense of the visual. Evidence supports that TFD and FC measures reveals where more viewer attention was required to cognitively process a visual (Chen et al., 2011). The relationship between processing ease and reports of aesthetic pleasure were examined.

Tobii Pro Studio software recorded, compiled, and exported data. To conduct a comparative analysis between presentation and teleprompter slide designs, a recording segment was chosen for analysis covering identical lecture content from one slide of each presentation. The segment was 25 seconds in duration and the entire slide (1920 x 1080) was activated as an area of interest (AOI). Tobii Pro Studio automates the classifications of fixations producing aggregated calculations of each fixation taking place at any location within the AOI.

\section{Aesthetic Pleasure and Liking}

Following the PowerPoint presentation video, participants completed the Aesthetic Pleasure in Design measure (APiD; see Blijlevens et al., 2004). A nine-item questionnaire was given to each participant. Each question has a response category asking for a measure of strongly agree to strongly disagree. Cronbach's $\alpha$ were: .93 for aesthetic pleasure and .83 for novelty. ${ }^{1}$

\footnotetext{
${ }^{1}$ Aesthetic Pleasure: (1) This is a beautiful PowerPoint. (2) This is an attractive PowerPoint. (3) This PowerPoint is pleasing to see. (4) This PowerPoint is nice to see. (5) I like to look at this PowerPoint. Novelty: (1) This is a
} 


\section{Verbal Behavior}

Participants completed a survey which included three open-ended questions about the video. Participants: (1) listed the main ideas and any information remembered, (2) identified the most memorable visual aspect, and (3) indicated their most memorable aspect of the entire presentation.

In preparation for the analysis of language data, the three responses to the questions were combined for each participant; combined responses with less than 10 words were omitted ( $M$ word count $=58.49, S D=34.54)$. Texts were corrected for common misspellings and elongations, then analyzed with Linguistic Inquiry and Word Count 2015 software (LIWC; Pennebaker et al., 2015). The LIWC software calculates the percentage of words belonging to 80 psychologically meaningful dimensions in each text, including self-referential language (“ $I$ ” words; $M=1.40, S D=1.96)$ and cognitive processing words $(M=11.69, S D=5.64)$. Scores were used to conduct statistical comparisons between teleprompter slide vs presentational slide groups.

\section{Results}

All participants (100\%) had previously experienced PowerPoint during classroom instruction. Participants reported experience with each slide category: 49.7\% presentation slides and 50.1\% teleprompter slides. The groups did not differ significantly on age, gender, or ethnicity.

novel PowerPoint. (2) This PowerPoint design is original. (3) This is a new example of a PowerPoint. (4) This PowerPoint is innovative. 
$\mathbf{R Q}_{\mathbf{1 A}}$. An independent t-test analysis found no significant differences between presentation $(M=22.13, S D=2.73, N=75)$ and teleprompter $(M=21.88, S D=3.16, N=$ 76) conditions for fixation duration, $t(149)=.51, p>$.05. Participants demonstrated equivalent fixation duration for both slide conditions.

RQ1в. An independent t-test analysis found significant differences between presentation $(M=60.29, S D=20.19, N=75)$ and teleprompter $(M=74.13, S D=17.9, N=76)$ conditions for fixation count, $t(149)=-4.46, \mathrm{p}<.001$. Participants demonstrated greater fixation count for the teleprompter slide condition.

RQ2. Participants reported greater aesthetic pleasure for presentation slides $(M=3.45, S D=.76, N=72)$ than teleprompter slides $(M=2.56, S D=.91, N=75)$. The difference was significant, $t(145)=6.52, p<.05$. Additionally, participants reported greater novelty for presentation slides $(M=2.85, S D=.86, N=72)$ than teleprompter slides $(M=2.00, S D=.81, N=75)$. The difference was significant, a $t(145)=6.2, p<.05$.

$\mathbf{R Q}_{3}$. Independent t-test analyses revealed meaningful significant differences in relation to participants’ self-referential language, cognitive language, and emotional language between teleprompter and presentation conditions. Compared to participants in the teleprompter slide condition $(M=1.08, S D=1.72, N=75)$, participants in the presentational slide condition $(M=$ $1.72, S D=2.19, N=73$ ) used more self-referential language in their responses to the PowerPoint presentations; $t(146)=1.98, p=.049,95 \%$ CI $=.00-1.29$.

Although there were no significant differences found between the presentational and teleprompter conditions in participants’ overall cognitive processing language ( $p=.664)$, participants in the presentational slide condition $(M=86.64, S D=16.22, N=73)$ used more analytic language in their responses to the PowerPoint presentation than participants in the 
teleprompter condition $(M=80.23, S D=23.05, N=75)$. This difference was marginally significant; $t(146)=1.96, p=.052,95 \% \mathrm{CI}=-.06-12.88$.

Participants in the teleprompter condition $(M=1.92, S D=2.39, N=75)$ used significantly more positive emotion words in the PowerPoint video compared to participants in the presentation condition $(M=1.21, S D=1.83, N=73) ; t(146)=-2.02, p=.045,95 \% \mathrm{CI}=$ $1.40--.02$

\section{Discussion}

This study explores multimedia learning via differential slide design to understand how learners process the textual versus visual representations while listening to a presentation. Eye tracking results indicate teleprompter designs produced more fixations. These higher levels of visual attention indicate greater strain placed on the eyes to interpret the textual information displayed on the slide (i.e., reading). Dual-coding impacted learners in the study when attempting to visual digest the text on the slide and comprehend the verbal message (see Clark \& Paivio, 1991; Paivio, 1971). Selecting what words to listen to or read presented a conundrum for learners.

Aesthetic survey results suggest a significant distinction between teleprompter and presentation slides, with participants reporting the presentation slide design style elicited a more positive aesthetic and novel experience. Viewers reported greater visual enjoyment for slide designed that demonstrated greater visual representations (i.e., pictures, images, etc.).

Cognitively, participants in the presentational slide design condition thought about the material more analytically, suggesting more active information processing. Language analyses revealed that, when writing about the PowerPoint content, participants in the presentational slide 
design condition may have processed the content more deeply in relation to themselvesinternalizing the material—indicating greater reflective learning.

\section{Pedagogical Interventions for Slideware Technologies}

Different categories of slide design yield contrasting learner reception, which presents new concerns for slide creation. Presentation slide design content was reported to be more easily viewable and digestible for learners. Viewers found presentation slides more visually appealing for consuming information and content internalization, which results in positive learning outcomes (Savoy et al., 2008). Slide design and aesthetics matter when sharing visual information for the facilitation of multimedia learning.

Eye tracking findings indicated that different slide design layouts, at least regarding FC, produce significantly different variations for teleprompter and presentation slide designs. Teleprompter slides required greater visual processing efforts to encode information and were more cumbersome to visually assimilate. While the amount of time spent fixating on a given slide was relatively the same, participants viewing teleprompter slides made more voluntary choices to fixate during separate instances—most probably due to the reading required on teleprompter slide designs. The eye must make sense of letters, then words, then sentences to understand them as coherent messages. With higher demands of FC, teleprompter slides demanded increased cognition in an attempt to comprehend the information communicated textually on the slide (and most likely ignoring the verbal message).

Aesthetics matter when creating slides. More pleasurable visual slide designs are less taxing on audience members deciphering the visual content. Moreover, participants reported a greater desire to engage slides if they find the viewing experience enjoyable (Burke \& James, 2008). Images and visual slides might be common within classroom environments, but effective 
use of visual narratives via presentation slides may be atypical, resulting in a novel aesthetic experience (see Knight et al., 2018; Medina, 2008). When attempting to gauge the appropriate size of a typeface for a slide or slide deck, it's best to avoid absolutes or certain ranges because type varies dramatically. A better approach is to put the slide deck into the "slide sorter" view at $66 \%$, if you are able to read the typeface on the screen then your audience will be able to read the type easily when projected for a presentation (Duarte, 2008). Aesthetic theory proposes a proportionally positive relationship between ease of processing and aesthetically pleasurable response. While the existence of a proportional relationship cannot be confirmed with this data, presentation slides functioned to simplify elements to a relevant image and selective text elicited a positive response from participants. Positive associations to course content—established visually with learners_-appear to encourage student attention via visual appeal.

When preparing to use slideware technology, it is important for instructors authoring slide decks to manage an effective balance between purposeful illustration over decoration in order to produce aesthetically appealing experiences with slides to produce positive learning outcomes. Technological integration for the classroom has the potential to augment instructional materials to encourage listener attention. Presenters should increase attention toward slide design to promote learner processing, and work to avoid overstimulation or to have slides function as entertainment as opposed to accentuating learning (Levasseur \& Sawyer, 2006).

\section{Implications for Teaching and Learning in the Classroom}

Slideware technology, like PowerPoint, is a concept-based multimedia technology. Here are some straightforward visual communication concept tips for users to enhance PowerPoint design for learners: 
(1) Wreck word walls: Findings suggest that information be simplified to essential text and a large singular visual element. Teleprompter and presentation slides both displayed a title orienting the viewer to the slide's main idea and date orienting the viewer to a time in history. In the teleprompter deck, ideas were simplified into textual bullet point representations. In the presentation deck, one image represented the content. Existing slides that are characteristic of teleprompter designs can be aesthetically enhanced by replacing bulleted text with a relevant image. Users looking to incorporate royalty-free and high quality images will find excellent options at any of the following: The Noun Project (https://thenounproject.com), Unsplash (htps://unsplash.com), and Pexels (https://www.pexels.com).

(2) Think cinematic: Findings suggest consistency across presentation slide decks to unite similar ideas and visually convey relationships are important for slideware technology communication. The presentation slide deck utilized a timeline structured visual content display and consistent horizontal push transitions to convey a linear temporal relationship from slide to slide. This encourages fluency by allowing viewers to anticipate and predict patterns of movement as the lecture unfolds, establishing an implied foundational lattice upon which students can begin exploring concepts. The location of the image, headline, and date remained consistent between concepts. Ruler and guide features allow users to build a grid that is consistent and coordinated for an entire slide deck (much like a visual organizational pattern).

(3) Craft a compelling visual: Findings suggest text-based slides produced an overall less enjoyable aesthetic experience. The bulleted slide layout most accurately fits the definition of a teleprompter slide in PowerPoint that defaults to a white background 
with black text. If instructors relied on this automation alone without making additional choices in visual communication such as incorporation of color, the slide deck runs the risk of forfeiting novelty. The presentation slide deck may appear more novel by incorporating visual elements that could not be achieved through textual documents.

(4) One idea = One slide: Findings suggest reducing the amount of text on slides proved to be effective in reducing the number of fixations required to process slides, which means increased processing fluency to help students quickly and efficiently engage with visually displayed concepts by identifying key ideas

(5) Build interactive content: Instructors face a critical question relating to visual pedagogy: Is students listening or reading more important? Simplification of slides can be achieved by substituting text with congruent imagery, which will assist instructors to isolate slides to a single idea. Students then are released from the burden of copying text and listening at the same time. The challenge involves how to transform PowerPoint to promote engagement in dialogue about course content that promotes probing questions instead of copying. The technology enhance active communication between student and teacher and among students.

\section{Limitations and Future Directions}

The nature of this study begins to question the comparability of differential slide designs. This study accounts for different visual displays of identical verbal information but cannot account for what was lost or gained visually in translation because there is no exact translation between slide designs. Further evaluative measures should be considered to higher degrees of specificity to reveal additional significant differences. 
This study occurred in a laboratory environment. Future investigations should set out to explore how students optically consume teleprompter and presentation slide designs in a classroom setting. Some aspects of participants’ viewing experiences are likely influenced by the absence of a physically present instructor or classmates. Fixation duration and fixation count could have been influenced by laboratory conditions, where participants were tasked with viewing a recorded lecture on a monitor as opposed to a larger projection often found in classrooms.

Cognitive recall should be evaluated in future research to explore how content is remembered via differential slide designs. Future examinations should be conducted that incorporate cognitive learning and recall immediately (and after a delayed period) following the visual presentations that integrate either teleprompter or presentation slides.

The aesthetic response reported in association with the simplified visual elements that characterize the presentation slide (image, headline, subtitle) supports the idea that processing fluency and aesthetics are inherently linked. Further inquiry is necessary to determine how aesthetic ease is experienced or influenced by the instructor (presenter) providing the verbal content that supplements the visual display.

\section{Conclusion}

Shifts in educational practice due to advances and access of multimedia technologies exhibit an unmatched opportunity for visual aid integration in the classroom. Findings from this study contribute a new layer of consideration to be applied to slideware technology and largely illustrates perceptions that disclose how students experience visual instructional messages. Slideware technologies are a concept-based technology that allows the findings of this study to be transportable to other slideware technologies (i.e., PowerPoint, Keynote, Prezi, etc.). The 
power of PowerPoint is its ability to facilitate visual representations in the learners' minds in a way that supplements an instructor's lecture by reinforcing the message. An important implication for multimedia learning is that decisions in visual message construction and design influence the degree to which students report an aesthetically enjoyable learning experiences. 


\section{Acknowledgements / Declarations}

[1] The datasets generated during and/or analyzed during the current study are available from the corresponding author on reasonable request.

[2] The author(s) received no financial support for the research, authorship, and/or publication of this article. 


\section{References}

Alley, M., \& Neeley, K. A. (2005). Discovering the power of PowerPoint: Rethinking the design of presentation skills from a skillful user's perspective. Proceedings of the 2005 American Society for Engineering Education Annual Conference \& Exposition, Portland, Oregon, June 12-15.

Axtell, K., Maddux, C., \& Aberasturi, S. (2008). The effect of presentation software on classroom verbal interaction and on student retention of higher education lecture content. International Journal of Technology in Teaching and Learning, 4(1), 21-33. http://www.sicet.org/journals/ijttl/ijttl.html

Boyd, R. L., \& Schwartz, H. A. (2021). Natural language analysis and the psychology of verbal behavior: The past, present, and future states of the field. Journal of Language and Social Psychology, 40(1), 21-41. https://doi.org/10.1177/0261927X20967028

Bucher, H., \& Niemann, P. (2012). Visualizing science: The reception of PowerPoint presentations. Visual Communication, 11(3), 283-306. http://doi.org/10.1177/1470357212446409

Burke, L., \& James, K. (2008). PowerPoint-based lectures in business education: An empirical investigation of student-perceived novelty and effectiveness. Business Communication Quarterly, 71(3), 277-296. https://doi.org/10.1177/1080569908317151

Chen, S., Epps, J., Ruiz, N., \& Chen, F. (2011) Eye activity as a measure of human mental effort in HCI. Proceedings of the 16th International Conference on Intelligent User Interfaces, 315-318. https://doi.org/10.1145/1943403.1943454 
Chi, M. T. H., \& Wylie, R. (2014). The ICAP framework: Linking cognitive engagement to active learning outcomes. Educational Psychologist, 49(4), 219-243. https://doi.org/10.1080/00461520.2014.965823

Clark, J. M., \& Paivio, A. (1991). Dual coding theory and education. Educational Psychology Review, 3(3), 149-210. https://doi.org/10.1007/BF01320076

Cooper, E. (2009). Overloading on slides: Cognitive load theory and Microsoft's slide program PowerPoint. Association for the Advancement of Computing in Education Journal, 17(2), 127-135. https://www.learntechlib.org/p/28143/

Coulson, D., \& Harvey, M. (2013). Scaffolding student reflection for experience-based learning: A framework. Teaching in Higher Education, 18(4), 401-413.

Dake, D. (2005). Aesthetics theory. In K. L., Smith, S., Moriarty, \& K. Kenney (Eds.) Handbook of visual communication: Theory, methods, and media, 3-22. https://ebookcentral.proquest.com

Davies, S., Higgins, K.M., \& Hopkins, R. (Eds.). (2009). A companion to aesthetics. Retrieved from https://ebookcentral.proquest.com

Duarte, N. (2008). Slide:ology: The art and science of creating great presentations. O’Reilly Media.

Depaepe, M. (2000). Order in progress: Everyday educational practice in primary schools, Belgium, 1880 - 1970. Leuven University Press.

Endicott, J. (2000). Growing up with PowerPoint. Presentations, 61-66. https://www.indezine.com/stuff/guppt.pdf 
Garrett, N. (2015). PowerPoint outside class: The impact of slide design on student use. Journal of Educational Technology Systems, 44(1), 69-85. https://doi.org/10.1177/0047239515598521

Herting, D. C., Pros, R. C., \& Tarrida, A. C. (2020). Habit and social influence as determinants of PowerPoint use in higher education: A study from a technology acceptance approach. Interactive Learning Environments. Online version. https://doi.org/10.1080/10494820.2020.1799021

Inoue-Smith, Y., \& Wang, S. (2016). College-based case studies in using PowerPoint effectively. Cogent Education, 3(1), 1127745. https://doi.org/10.1080/2331186X.2015.1127745

Knight, E., Paroutis, S., \& Heracleous, L. (2018). The power of PowerPoint: A visual perspective on meaning making in strategy. Strategic Management Journal, 39, 894-921. https://doi.org/10.1002/smj.2727

Levasseur, D. G., \& Sawyer, J. K. (2006). Pedagogy meets PowerPoint: A research review of the effects of computer-generated slides in the classroom. Review of Communication, 6(1-2), 101- 123. https://doi.org/10.1080/15358590600763383

Mann, S., \& Robinson, A. (2009). Boredom in the lecture theatre: An investigation into the contributors, moderators and outcomes of boredom amongst university students. British Educational Research Journal, 35(2), 243-258. https://doi.org/10.1080/01411920802042911

Mayer, R. E. (1994). Multimedia learning: Are we asking the right questions? Educational Psychologist, 32(1), 1-19. https://doi.org/10.1207/s15326985ep3201_1

Mayer, R. E. (2001). Multimedia learning. Cambridge University Press. 
Mayer, R. E., \& Sims, V. K. (1994). For whom is a picture worth a thousand words? Extensions of a dual-coding theory of multimedia learning. Journal of Education Psychology, 86(3), 389-401. https://doi.org/10.1037/0022-0663.86.3.389

Medina, J. (2008). Brain rules: 12 principles for surviving and thriving at work, home and school. Pear press.

Motamedi, V. (2019). The promises of presentational technology for teaching and learning. Journal of Education and Learning, 13(3), 416-419. https://doi.org/10.11591/edulearn.v13i3.13175

Nelson, R. S. (2000). The slide lecture, or the work of art 'history' in the age of mechanical reproduction. Critical Inquiry, 26(3), 414-434. https://www.jstor.org/stable/1344289

Paivio, A. (1971). Imagery and deep structure in the recall of English nominalizations. Journal of Verbal Learning and Verbal Behaviors, 10(1), 1-12. https://doi.org/10.1016/S00225371(71)80086-5

Paivio, A. (1986). Mental representations: A dual coding approach. Oxford University Press. Penciner, R. (2013). Does PowerPoint enhance learning? Canadian Journal of Emergency Medicine, 15(2), 109-112. https://doi.org/10.2310/8000.2013.130756

Pennebaker, J. W., Boyd, R. L., Jordan, K., \& Blackburn, K. (2015). The development and psychometric properties of LIWC2015. University of Texas at Austin.

Perusso, A., Blankesteijn, M., \& Leal, R. (2020) The contribution of reflective learning to experiential learning in business education. Assessment \& Evaluation in Higher Education, 45(7), 1001-1015. https://doi.org/10.1080/02602938.2019.1705963 
Reber, R., Schwarz, N., \& Winkielman, P. (2004). Processing fluency and aesthetic pleasure: Is beauty in the perceiver’s processing experience? Personality and Social Psychology Review, 8(4), 364-382. https://doi.org/10.1207/s15327957pspr0804_3

Reiber, L. P. (1990). Animation in computer-based instruction. Educational Technology Research and Development, 38, 77-86. https://doi.org/10.1007/BF02298250

Rello, L., Baeza-Yates, R., Dempere-Marco, L., \& Saggion, H. (2013). Frequent words improve readability and short words improve understandability for people with dyslexia. Proceedings from the International Federation for Information Processing Conference on Human-Computer Interaction. https://doi.org/10.1007/978-3-642-40498-6_15

Reynolds, G. (2012). Presentation Zen: Simple ideas on presentation design and delivery (2 ${ }^{\text {nd }}$ ed.). New Riders.

Savoy, A., Proctor, R. W., \& Salvendy, G. (2008). Information retention from PowerPoint and traditional lectures. Computers \& Education, 52(4), 858-867. https://doi.org/10.1016/j.compedu.2008.12.005

Shapiro, E. J., Kerssen-Grip, J., Gayle, B. M., \& Allen, M. (2006). How powerful is powerpoint? Analyzing the educational effects of desktop presentational programs in the classroom. In B. Gayle, R. Preiss, N. Burrell, \& M. Allen, M. (Eds.), Classroom communication and instructional processes: Advances through meta-analysis (pp. 61-76). Lawrence Erlbaum.

Tausczik, Y., \& Pennebaker, J. (2010). The psychological meaning of words: LIWC and computerized text analysis methods. Journal of Language and Social Psychology, 29(1), 24-54. https://doi.org/10.1177/0261927X09351676 
Vazquez, J., \& Chiang, E. (2014). A picture is worth a thousand words (at least): The effective use of visuals in the economic classroom. International Review of Economics Education, 17, 109-119. https://doi.org/10.1016/j.iree.2014.08.006

Wang, J., Mendori, T., \& Hoel, T. (2019). Strategies for multimedia learning object recommendation in a language learning support system: Verbal learners vs. visual learners. International Journal of Human-Computer Interaction, 35(4-5), 345-355. https://doi.org/10.1080/10447318.2018.1543085

Zagermann, J., Pfeil, U., \& Reiterer, H. (2016). Measuring cognitive load using eye tracking technology in visual computing. Proceedings of the sixth workshop on beyond time and errors on novel evaluation methods for visualization, 78-85.

https://doi.org/10.1145/2993901.29939 
Figure 1. Slide Design Category Exemplars.

Teleprompter Slide

\section{Public Speaking: $500 \mathrm{BCE}$}

-Ancient Greece

- Oratory

- Logography

- Ars Oratoria: the art of public speaking

- Serves as a mark of professional competence - Politicians and lawyers

Presentation Slide

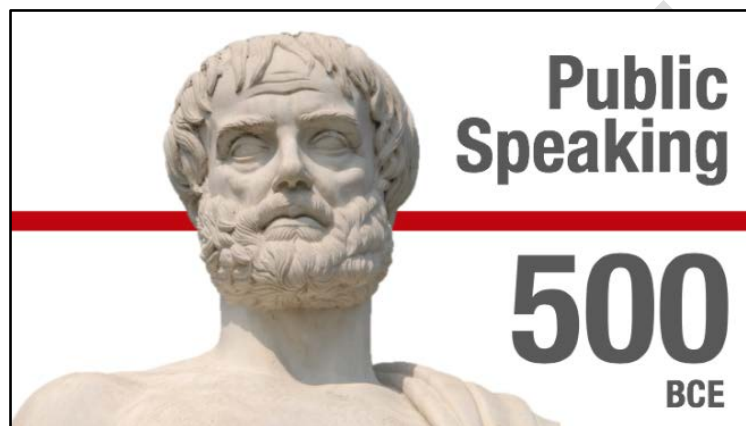

